two chapters, the authors attempt to relate endocrine mechanisms to the natural life of the animal and here the gaps in our knowledge become abundantly clear. In chapter five, Koch (Louvain) considers the mysteries of migration, principally the salmonids and the eels. $\mathrm{He}$ presents the problems and poses the questions with clarity but, for the most part, the answers are not known. Baggerman (Groningen), in the sixth chapter, brings together all the available data in fishes of the influence of hormones on behaviour patterns. Application of these to normal breeding cycles and alterations in behaviour is difficult and her chapter is rewarding in presenting concepts and theories to stimulate further investigation in this burgeoning field. In chapter seven, Van Oordt (Utrecht) describes the various types of cells in the adenohypophysis of the major classes of Amphibia and fish. The cells are differentiated by a series of staining reactions and as far as possible they are related to the adenohypophysial hormones which they may secrete Van Oordt wisely points out that positive identification of pituitary cells cannot necessarily be made by stains alone because correlated experimental findings are required. The colour plates, essential in this type of work, are well produced, and the chapter itself is a model of critical analysis of a field wherein there is much confusing literature. The last chapter by Barker Jørgensen (Copenhagen) deals with the central nervous control of adenohypophysial functions. This is an area which is being actively investigated in mammals and knowledge of the lower vertebrates, particularly of the amphibians, is accumulating. The nature of the central nervous system factors which influence the pituitary has been indicated for mammals though not with certainty, and it is not known at all for the lower vertebrates. Barker Jørgensen gives a thorough review of the present status of hypothalamic-pituitary interrelationships and he points the way to further work which may, indeed, illuminate problems in the mammals, the class on which the endocrinologist in the past has largely relied.

This book confirms the emergence of the endocrinology of the lower vertebrates as a legitimate field in its own right. There were always laboratories interested in sub-mammalian vertebrates, but as endocrinology grew in the $1920 \mathrm{~s}$ and $1930 \mathrm{~s}$ the majority of investigators sought knowledge from the few eutherian species of laboratory animals and from clinical observations. The richness and abundance of vertebrate and invertebrate species were largely ignored and it is pleasing to record that this is being rectified and that comparative endocrinology, with its own journals and societies, is making significant contributions to the corpus of knowledge. The book under review is one of the latest in a rapidly expanding library concerned with the subject. It is excellently written and produced, and well illustrated. The material is presented in a careful and critical manner and the book is valuable not only for the facts it contains but also for its emphasis on those areas which urgently require investigation. Much has to be done in the identification of hormones, their action in the natural life of the animal, and their biochemical and cellular modes of action. More species are being examined, but these are only a tiny fraction of those available in a great variety of habitats. The process has been started and the authors and editors are to be congratulated for setting out so well some of the problems in perspective. IAN Chester Jones

\section{MOULDS IN INDUSTRY}

An Introduction to Industrial Mycology

By George Smith. Sixth edition. Pp. ix + 390. (Arnold: London, February 1969.) $80 s$.

THE death of George Smith in 1967 was a great loss to mycologists, but fortunately he had revised the text of his book, then in the fifth edition. It is certain that the new edition will be as well received as those which preceded it, and that it will occupy with distinction a place on the shelves of mycologists whether they are concerned with research or teaching.

The text of the sixth edition takes into account the more important publications in industrial mycology and brings changes in nomenclature into line with modern opinion. Clear descriptions are given of most of the genera of fungi which regularly occur on industrial products, and emphasis has appropriately been placed on those species which are of the greatest importance. The Fungi Imperfecti, particularly the genera Aspergillus and Penicillium, have been dealt with in considerable detail, with 145 pages out of the total of 190 pages occupied by descriptions of organisms being devoted to this class. The remainder of the book deals with laboratory equipment and technique, the physiology of moulds, the maintenance of a culture collection, the control of mould growth and industrial uses of fungi. An important addition to the text is the inclusion of a separate chapter on mycology of the soil, a subject which was previously, but rather inappropriately, given somewhat brief consideration in the chapter dealing with the industrial uses of fungi. Useful chapters on mycological literature and microscopy are included. Throughout the text, reference is made to recent developments both in the growing and examination of fungi and in their industrial uses. The author's wide experience of fungi and mycological techniques is freely communicated to readers and will be very warmly appreciated by experienced mycologists as well as by newcomers to the subject.

The numerous photomicrographs are characterized by their high quality and add greatly to the value of the book. Only two figures appearing in the fifth edition have been omitted, but seven new jllustrations have been introduced. The latter include photomicrographs of Streptomyces sp., Cladosporium resinae, Curvularia sp., Stachybotrys echinata, Aspergillus ustus and Gliocladium deliquesiens.

The revised book consists of 390 pages as compared with 399 pages of the previous edition. This reduction in page number accompanied by the addition of new material has been achieved by the use of more words per page without loss of the high quality of printing and production.

\section{JOHN COLHOUN}

\section{LIGHT APPLIED TO BIOLOGY}

\section{Techniques of Photostimulation in Biology}

Edited by B. H. Crawford in association with G. W. Granger and R. A. Weale. Pp. 317. (North-Holland: Amsterdam; Wiley (Interscience): London and New York, 1968.) 117s.

THIs book almost enables the reader to visit several leading laboratories in which light is applied to biology. The curiosity and admiration of all with appropriate interests cannot fail to be aroused and each may benefit from a crowded notebook. A practical survey of photic techniques is made by G. W. Granger in the introduction.

B. H. Crawford has acted as a presiding genius, making generous contributions which suitably dominate most of the book, but with some evidence of thoughtful restraint. Few hobby horses have been ridden, although the exceptions add to a lively style. The format, line diagrams and general production are good but not lavish. This is an arresting volume to which the postgraduate will turn for reference and to which undergraduates in many fields might well be directed for inspiration. There is scope for at least one companion volume.

Physics is the basic point of entry to vision for most of the seven authors; it is therefore the fundamental emphasis throughout. A relatively long chapter by R. A. 